of the active population who cannot go to the schools but only receive instruction of a vocational type. I remember seeing the positive results achieved in the area of the Tennessee Valley Authority, where private farms were used for experimental purposes.

I think we should reconsider connexion between general and vocational education. They should not be thought of as separate types of education, because in a certain sense they are complementary. In some cases it will be necessary to emphasize general education, in others vocational education. One must take account of the age of the farmers and of the people to be instructed. For general education, dealing with young men, it is possible to give some vocational instruction and education. For the older people it is difficult to give general education; it is easier to begin with experimental work, and to give some vocational education, based mostly on discussions, as opportunity arises.

The example of the Papaloapan region has been quoted. The new opportunities opened up there by providing new houses and villages were abandoned when the farmers returned to the primitive life. This was a result, probably, of not giving them the necessary education. There should have been discussions and elementary instruction to convince the farmers that it would be possible for them to have better standards of living if they were properly instructed in the technical side of their work. Both general and vocational education are needed, but the emphasis on the one or the other should be varied according to the particular conditions.

\title{
(2) THE SOCIOLOGICAL ENVIRONMENT
}

E. W. HOFSTEE

Wageningen Landboushogeschool, Netherlands

NE of the least well developed sectors of sociology is still
economic sociology. When one looks at the leading journals
in this field, one sees that the number of articles devoted to economic
behaviour is, relatively, extremely small, though every sociologist
will acknowledge that economic behaviour is a very important part
of social behaviour as a whole. This does not mean that amongst the
enormous quantity of sociological literature which has been written,
especially during the last few decades, economic sociological publica-
tions are totally lacking. Taken together, many boolsshelves could 
be filled by books and articles on subjects related to economic sociology. But that does not alter the facts that the contacts of sociologists with economic life are rather incidental, and that economic sociology has not yet achieved the same status in sociology as a whole as have many other branches of this science. ${ }^{\mathrm{I}}$ An exception has perhaps to be made for so-called industrial sociology, a rather specialized and narrow branch of sociology, which is not at all a sociology of economic life in an industrialized society, as its name promises, but only the sociology of industrial enterprise. ${ }^{2}$

The best situation we find probably in rural sociology. Most of this developed within institutes for higher education and research devoted to the furtherance and development of agriculture as an economic activity. So rural sociology could hardly avoid economic behaviour, and though this science has developed to a sociology of rural life in general, interest in economic behaviour as a part of social behaviour is almost general with rural sociologists. On the other hand, tural sociology is a part, and a rather young and relatively small part, of sociology as a whole, and it has not yet been able to compensate for the shortcomings of sociology in general in the field of economic sociology.

This means in this concrete case that there is not yet a well developed, more or less generally accepted, body of theory of the sociological conditions of economic gtowth. When I try to give here an outline of what is the important sociological background of this economic development, you have to bear in mind that much of what I say is still hypothetical or needs at least further confirmation.

Sociologists can look at economic growth from many points of view, all of which are interesting and of importance for the understanding of the phenomenon. We can be interested in economic growth in relation to leadership, to social stratification, to type of family life, to urbanization, and so on. It seems to me that the most essential and embracing sociological problem related to the phenomenon of economic growth is that of social change. That there exists a relation between economic development and social change no one will deny. But not all relations between economic development and social change are of importance with regard to our subject. The fact that economic growth as a rule leads to changes in other spheres of social life offers a number of interesting sociological problems, but

\footnotetext{
I An example of a recent textbook in which adequate attention is given to economic sociological problems is H. M. Johnson, Sociology, I96o.

${ }^{2}$ For some temarks on the difference in character of industrial sociology and rural sociology see: E. W. Hofstee, 'Agriculture and Rural Life in an Industrialising Society', Transactions of the Fourth World Congress of Sociology, vol. ii, I959, pp. I3-28.
} 
to follow them up would not help us very much to understand the sociological conditions for economic growth.

We come nearer to understanding the fundamental importance of these conditions when we appreciate that economic development is always social change in the sense of change in the social relations between the human beings involved, change in their culture, and change in their behaviour as it is conditioned by social structure and culture. When a group of subsistence farmers begin to increase their production, begin to specialize, and begin to sell their products in the market, then this process not only leads to social change but is social change. It means entering into relations directly or indirectly with people outside their village whom they have considered till now, perhaps, as foreigners and whom they have probably distrusted. It means perhaps taking credit to finance the expanded business. And that again means, as facts show, a fundamental change in the way of thinking of the peasant because, traditionally, he considered loans as essentially wrong. It means perhaps that co-operatives have to be established to sell the products and to buy commodities which the peasant needs in the new conditions. It means perhaps change in the organization of the labour force working on the farm. It means certainly the abolition of a number of customs which, traditionally, played an important role in the life of the farmers individually and in the community as a whole. It means also the necessity to make calculations which the subsistence-farmer never did before.

Not all economic development implies equally important social change, of course. When for example the population increases in a tegion where abundant land of good quality is available, this will perhaps lead only to an increase of the acreage of cultivated land, without changes of importance in the system of production and without change of importance in social life in general in which this system of production is embedded. But such cases are rare. It is also possible for economic growth to develop so very slowly that it is almost imperceptible and the change in social life involved is not recognized as such by the population.

But economic growth as it has occurred in agriculture in the more highly developed countries in the last seventy-five years or longer, and as considered necessary at the moment in the so-called underdeveloped countries or under-developed regions, is part of, and cannot exist without, a rapid and complex process of social change of which, just because of its speed, most of the population must be conscious.

This leads to the conclusion that for economic growth of any 


\section{Environmental Conditions for Agricultural Development}

importance it is essential that the population in question be willing to accept social change. This holds for agriculture, at least for agriculture in the non-communist countries, even more than for industry. In industry economic development is for the greater part dependent on the willingness to accept change of a rather small number of people at the top of the concerns, though the willingness in this respect of the labourers is certainly not without importance. But in agriculture this willingness has to penetrate the minds of a multitude of farmers and peasants before it can influence the economic behaviour of the population as a whole.

Numerous investigations made during the last few decades by rural sociologists have shown again and again that the greatest obstacle to the development of agriculture originates from the fact that so many farmers are not willing to accept the change in their individual and their group life which is an unavoidable condition for this development. . This often occurs even in cases where the agricultural population is well aware of the attractions of a higher standard of living in the modern world and would like to share it.

Even in the most highly developed countries a great number of farmers resist the social change necessary for economic development, or at least are very reluctant to accept it. In some of these countries there are still regions where hardly any development of agriculture is perceivable, though all necessary information about modern agriculture is easily available and the government and private organizations do their utmost to bring agriculture up to a higher level. ${ }^{2}$

I See the many publications of American rural sociologists on the adoption of new farm practices. Most of these publications are mentioned in the recent Bibliography of Research on Social Factors in the Adoption of Farm Practices, 2nd edition, Iowa State College, I959. Also several publications of the Department of Rutal Sociology of the Agricultural University of Wageningen (Nethetlands), as, for example, A. W. van den Ban, Enkele kenmerken en eigenschappen van vooruitstrevende boeren, Part I, Bulletin No. 5, 1957, and Part II, Bulletin No. 10, I958, of the Department of Rural Sociology, Wageningen; E. Abma, Boer en coöperatie in Nederland, Part I, Bulletin No. 2, I955, and Part II, Bulletin No. I2, I958, of the Department of Rural Sociology, Wageningen; A. J. Wichers, De beoefening van de bloemisterij en de groenteteelt te Bebsd, Bulletin No. 3, I957, of the Department of Rural Sociology, Wageningen; E. W. Hofstee, Sociologische aspecten van de landbounvoorlichting, Bulletin No. I, I953, of the Department of Rural Sociology, Wageningen; A. W. van den Ban, 'Locality Group Differences in the Adoption of New Farm Practices', Rural Sociology, vol. xxv, pp. 308-20; B. Benvenuti, Farming in Cultural Change. In Germany interesting tesearch was done by von Blanckenburg ( $P$. von Blanckenburg, Bäterliche Wirtschaftsfilhrung in Kraftfeld der sozialen Umwelt, Schriftenreihe für ländliche Sozialfragen, Heft 26,1960 ), in France by Mendras ( $H$. Mendras, Attitudes des agriculteurs du Sundgau vis d vis de la modernisation de l'agriculture, (2959). In India Bose has started research in this field (S. P. Bose, Characteristics of Farmers who Adopt Recommended Agricultural Practices in Some Selected Villages in WTest Bengal, I959 (mimeographed)).

${ }^{2}$ A typical example of a traditionalistic rural community in Italy is given by Moss and 
To understand why this is so one has to bear in mind that in human society social change is abnormal. For ages mankind lived in a world which hardly showed any change at all or at least not a change which was consciously experienced as such. It is true that several civilizations in the past rose to such a level that social life showed a much quicker change than was normal in the surrounding world. But it is only in our modern world, since the end of the eighteenth century, that social change has become an important element in the daily life of the population and that people have become conscious of the fact that the world is a changing one.

Change as such is important, but perhaps even more important from our present point of view is the attitude towards change. Man's outlook on life has been almost always a traditional one. The norms for human behaviour were found in the past. Things had to be as they always had been. What was done by the past generations was well done and should be done by the future ones. This attitude was expressed and symbolized by the great power and the dominating influence of the old people in almost all past civilizations. Even in traditionalistic societies sometimes change was unavoidable. But in that case those who had to convince the population of the necessity of this change mostly preferred not to present it as innovation and improvement and not even as a change but as a return to old customs and conditions which, for unhappy reasons, had been lost. Perhaps in a very few of the civilizations of the past, especially in the Greek civilization in its heyday, there was a beginning of a revolt against traditionalism, but it was only in modern civilization that it lost its dominant power in society. It is only in the last two hundred years that people have learned more and more to accept change as something which is essentially necessary for the well-being of the individual and of society. In modern society we may differ as to the kind of change which is most desirable and as to the degree of change and the speed at which it should be realized, but the conviction that change is not only unavoidable but that it is a way of improving our living conditions has become ever more general. Our society has become really dynamic in the sense that change has become normal and -how paradoxical it may sound-part of the routine of our daily life.

In my opinion the acceptance of change as normal and as right in principle is the most essential characteristic of modern culture. It is

Cappannari in their study of a village in southern Italy (L. W. Moss and S. C. Cappannari, A Sociological and Anthropological Investigation of an Italian Rural Community, I959 (mimeographed)).

I This does not mean, of course, that all non-modern societies are alike. But from the 
the root of almost all other characteristics of this modern culture and makes it clearly distinct from all other cultures, present and past. It is, I believe, more essential than other phenomena which are sometimes used to characterize modern society, such as capitalism, industrialization, urbanization, and rationalism. Part of these phenomena are only aspects of this acceptance of change, part of them are its consequences or are dependent on it to a high degree for their existence. It penetrates all material and non-material aspects of modern culture. Our modern culture is perhaps best indicated by the word dynamic.

The first clear symptoms of this modern revolt against traditionalism we find in Italy in the Renaissance. For a long time this nontraditionalistic way of thinking was shared only by a small group of intellectuals and a few exceptional men in trade and government. Their influence was important, but they were not representative of the society as a whole. It is only in the second half of the eighteenth century that it begins to penetrate the minds of a great number of the members of the middle class, especially of the upper middle class, in several west European countries. From the upper middle class this new way of thinking reached the lower classes in course of time. The modern dynamic pattern of culture is now dominating our society, but in fact the process of its gradual acceptance is still under way. Not even in the more highly developed countries is it accepted everywhere and by everyone. Even in the most advanced countries remnants of traditionalism are still to be found.

In general the modern pattern of culture reached the countryside rather late. This was not only, and perhaps not even primarily, a consequence of geographical isolation. In some parts of Europe, where a class of well-to-do, large farmers existed in the eighteenth century, we find an early development of modern ways of thinking, in some cases as far back as that century. ${ }^{\mathrm{x}}$ But the majority of the agricultural population did not consist of well-to-do, self-assured farmers but of poor, modest, self-contained peasants who belonged to the least privileged classes in society. They, as well as other social groups on the lower rungs of the social ladder, came tather late into contact with this modern dynamic Western culture. For a great part, probably by far the greatest part of the countryside in the Western world, this process of acceptance of the modern pattern of culture began

point of view which is interesting us here, it is not necessary to differentiate the various types of traditionalistic society as for example between folk societies and peasant societies.

For an example of a rural society where a modern mentality came into being in the eighteenth century, see E. W. Hofstee, Het Oldambt, Deel I, Vormende Krachten, I937. 
only at the end of the nineteenth century. There it is not yet complete, often far from complete. In the so-called under-developed countries it has hardly begun. The struggle between the traditionalistic and the modern dynamic culture in my opinion is almost everywhere the most important feature of social life in the countryside. It is the most essential element of what is often called the modernization or urbanization of the rural areas. The term urbanization, I believe, is not quite right, because the modern dynamic culture is not typically urban, even if it was generally, though not always, accepted earlier in the towns and cities in a certain region than in the countryside. It is important to point out that there are not only regions which are relatively traditionalistic and other regions which are relatively modern but that in every region we find farmers on different levels in a continuum running from traditionalistic to truly dynamic. Even in a country where change as a means to improvement is so widely accepted as in the United States of America, farmers in a certain region show remarkable differences in their willingness to accept change, as appears clearly in research findings. But there are very important differences between the various countries and regions as a whole so far as their places in the continuum are concerned.I

Summarizing the reasons I have set out, our conclusion is that economic development in agriculture depends to a high degree on the willingness of the farmer to accept change, that in any concrete case this is dependent on his attitude towards change in general, that this attitude is determined for the greater part by the degree to which he has accepted the modern pattern of culture, and that a favourable attitude towards change is even the most essential characteristic of this modern, as opposed to the traditional, culture.

That the inclination to consider change as good in principle and as necessary for the improvement of the well-being of the individual and of society is the most essential element in modern culture, is not a conclusion which can be sustained by exact evidence of course; it is partly a question of subjective valuation and is open for discussion. But the rest of the conclusions can be corroborated, I believe, by facts and figures.

As I have mentioned already, numerous investigations have shown that successful farming and therefore economic development in agriculture is highly dependent on the willingness of the farmer to

I The concept of a continuum running from traditionalistic to modetn-dynamic was clearly developed by B. Benvenuti in his study of the community of Winterswijk in the Netherlands (B. Benvenuti, Farming in Cultural Change). 
accept change. These investigations have shown also that this willingness was not just an accidental, more or less independent, trait of the individual mind, but that it was cleatly related to the social and cultural conditions under which the farmer was educated and under which he lived. The majority of the studies in this field have been carried out in the United States of America. Several tural sociologists in that country have tried to bring under a general heading-as, for example, the degree of urbanization, or the degree of rationalization ${ }^{\mathrm{r}}$ - the conditions which favoured the development of a positive attitude to change and, because of that, favoured successful farming. One of the first American studies in this field emphasized the importance of the general cultural background of a certain group of farmers for the acceptance of certain new farm practices. ${ }^{2}$ Nevertheless it is remarkable that American rural sociologists have not tried, or have seldom tried, to correlate the willingness to accept technical change in agriculture with the degree to which the farmer participates in the essential aspects of modern dynamic culture. ${ }^{3}$ But it seems to me that the findings of the American rural sociologists fit into the conception that the willingness to accept change, including technical change, is part of a general pattern of culture of which the positive attitude towards change is probably the most essential element and which penetrates all sectors of human life.

In a number of investigations carried out by the Department of Rural Sociology of the Agricultural University of Wageningen we have used a direct cultural approach, so far successfully. It has proved possible to indicate by a simple scale the place of the farmers in the communities we have investigated in a continuum running from traditionalistic to modetn dynamic. It can be shown that the farmers who scored low in this scale are characterized by cultural traits quite different from those characteristic for the farmers who scored high. The totality of the cultural traits we found with the

\footnotetext{
I Interesting is the study of Dean et al. in which the authors tried to introduce rationality as an intervening variable between a number of independent variables and the adoption of new farm practices (A. Dean, H. A. Aurbach, and C. P. Marsh, 'Some Factors Related to Rationality in Decision Making among Farm Operators', Rural Sociology, vol. xxiii, pp. I2I-35).

${ }^{2}$ C. R. Hoffer, Acceptance of Approved Farm Practices among Farmers of Dutch Descent, Michigan Agricultural Experiment Station Special Bulletin 3 IG, I942.

3 Near to a cultural approach comes F. L. Campbell. He tries to telate the use of information sources to some personal and social variables. He uses as a theoretical model for his study the so-called localite-cosmopolite model. The localite-cosmopolite dichotomy is related to 'Tönnies' Gemeinschaft-Gesellschaft dichotomy and several other concepts of that kind. It has some relation also to our traditionalistic-dynamic continuum. H. L. Campbell, Factors Related to Differential Use of Information Sources, Rural Sociology Report No. Io, Iowa State University, I959.
} 
sub-group of the farmers who scored low on the one hand and that for those with a high score on the other hand were clearly consistent wholes from a socio-psychological point of view. This confirmed not only that traditionalistic and modern farmers show different cultural traits, but that those different traits form real patterns, even if the transition from one pattern to the other is gradual. ${ }^{\mathrm{I}}$

These different patterns are correlated with quite different types of social behaviour, including economic behaviour. It is impossible to give here a complete picture of the differences in economic behaviour which we found. The modern dynamic farmers were far ahead of the traditionalistic. In one community we divided the farmers into three groups according to their score in the scale we used to measure their place in the continuum from traditionalistic to modern. We found that, other conditions like size of farm, \&c., being the same, the group showing the highest score earned a yearly income about 30 or 40 per cent. higher than the lowest score. But even more important is it that, without the modern dynamic sub-group in the community, there would be hardly any economic development. They are the innovators, who after some time are followed slowly by the traditionalistic farmers. Our findings do not, of course, yet allow worldwide generalizations. But as I have mentioned already, it seems to me that the results of the findings in other countries agree with our results.

The next step, of course, and from the practical point of view the most important one, is to find out why farmers are modern or traditionalistic. Up to now our findings do not suggest that inborn qualities are of great importance in this respect. The findings in other countries with regard to the acceptance of new farm practices seem to cotroborate this conclusion. This means that the degree to which the modern pattern of culture has penetrated certain regions and communities and certain sub-groups in these regions and communi-

I That a certain pattern of culture is chatacteristic for modern farmers does not mean, of course, that they are all alike and behave alike. Modernism is only a part-be it an important part-of the personality of the individual. Besides, modern farmers can live under different conditions and that means also that their behaviour can vary. Therefore not all cultural traits which are related to the modern pattern of culture will be equally strong with all individuals who can be classified as modern. But when we compare groups of modern farmers there appears, so far as our experience goes, a basic similarity in the pattern of culture of the groups as a whole. When Menzel et al. (H. Menzel, J. Coleman, and E. Katz, 'Dimensions of Being "Modern" in Medical Practice', Journal of Chronic Diseases, vol. ix, pp. 20-40) find four distinct dimensions of being modern in medical practice, this does not mean that there is not one modern pattern of culture, but that on the basis of this one underlying pattern of culture different ways of modern behaviour can develop and that it is possible to distinguish certain types in these different kinds of behaviour. 
ties is dependent on the degree to which they are open to cultural influences from the outside. For even if it would not be right to consider those who accept modern culture as only passive, the primary influences from which originates the modenn way of thinking of our farmers come from outside.

One of the most outstanding characteristics of the modern dynamic farmers as compared with the traditionalistic farmers, according to our findings, is the great interest in what happens in the world outside their farms and outside their communities. They have their own standpoint with regard to things which matter in this outside world, while the traditionalistic farmer when asked about these problems will tend to answer: 'I do not know'.

But what are the conditions which help or hamper the penetration of cultural influences from the outside? Basically it is a question of the degree of socio-cultural isolation. What, then, causes and what prevents isolation? Future research will give us a better insight in this respect, but some provisional partly obvious conclusions can already be drawn. The degree of geographical isolation is important. Even in modern countries which as a whole are opened up for modern transport, local differences in quality and quantity of roads cannot be neglected. So we found in a rural community in the Netherlands, a significant correlation between the degree to which the modern pattern of culture had been accepted and the distances from the farms to the metalled road. ${ }^{\mathrm{I}}$ It is hardly necessary to stress the importance of the means of transport and communication. Modern transport and modern means of mass communication are now threatening traditionalism in all parts of the world. Important also is the degree of education taken in the widest sense. Though not all investigations show the same results, it seems that general education is of special importance and that the role of formal technical education in agriculture should not be over-estimated.

More interesting from the sociological point of view are the causes of the continuation of traditionalism which have to do with the less obvious characteristics of social groups in question. Very important are the attitudes of the population towards outsiders and especially towards the government and its representatives. In peasant communities there is often a strong distrust of outsiders but the degree of this distrust and the chance to break it down depend very much on the character of the government, the state of public affairs and public morals in general, including the morals in trade and commerce.

I Benvenuti, op. cit. 
Bad government past and present greatly hampers the acceptance of modern ideas by the farmers. ${ }^{x}$

The type of social structure is also of influence. Strong class and caste differences, and the resulting lack of communication between the higher-who are normally the first to accept the modern pattern of culture-and the lower may retard the movement. Small farmers often have the feeling that modernization of farming is something for the 'big ones' and that it would be unsuitable if they tried to imitate them. ${ }^{2}$

Self-created socio-cultural isolation of small groups, for example sectarian groups, may lead to non-acceptance of the modern pattern of culture. It seems to depend partly on the size of the group. If it is large enough to have sufficient competent social and intellectual leaders they will often modify the modern pattern of culture to suit their own needs so that it will be acceptable for the members of the group. But when the group is small, the members often consider any symptom of a changing culture which they perceive in outsiders as wrong.

Haller's investigations lead to the conclusion that a firm conviction of farmers' sons that they want to become farmers often causes a certain cultural isolation and a more traditionalistic frame of mind. ${ }^{3}$ His findings are corroborated to some extent by our own. Modern

x It seems an acceptable hypothesis that the extreme backwardness of agriculture and the resistance against change in southern Italy and some parts of Ireland is caused, at least pattly, by a deep distrust of government agencies in the past.

${ }^{2}$ See, for example, $\mathrm{H}$. Mendras, Pour une analyse compréhensive de la diffusion du progrès agricole, I959, mimeographed. A. K. Constandse, 'Sociale hierarchie in Kamerik', Mens on Maatschappij, vol. xxix, pp. 293-307 and 342-62, showed that in a seemingly fairly homogeneous rutal community thete were almost no informal relations between groups of farmers of different social prestige.

3 A. O. Haller, 'The Occupational Achievement Process of Farm-Reated Youth in Urban Industrial Society', Rural Sociology, vol. $\mathrm{xxv}_{3}$ pp. 32 $\mathrm{x}-33$. Haller shows that farmers' sons who plan to become farmers have a lower level of educational and occupational aspiration than those who plan to find jobs outside agticulture. They show a lack of interest in extended education and in information about the outside urbanindustrial world in general. There is a suggestion in Haller's paper that the mentality of those who plan to farm is to be considered as a right adjustment to a future life as a farmer. He quotes Strauss, who remarks that those who plan to farm have values functionally useful to farming. I doubt if this is right. Several of the characteristics Haller finds for the boys who plan to become farmers are the same we find for traditionalistic farmers. Modern dynamic farmers-which means from the eçonomic point of view, good, successful farmers-show, for example, a great interest in the world outside their own community, including non-agricultural affairs. As a rule, too, they are interested in extended education for their children. In his study of the Dutch community of Dantumadeel A. Bergsma found that sons of modern dynamic farmets, who resemble Haller's boys who ate planning to find non-agticultural jobs, are usually successful in nonagricultural occupations, while sons of traditionalistic farmets, who resemble Haller's boys who plan to farm, are as a rule not successful. 
farmers consider it normal that a man should try to find another job when he cannot earn a decent living in agriculture and they do not consider it self-evident that their children should become farmers.

In the foregoing only a few factors which influence the development of a modern pattern of culture as affecting farmers are discussed. More could be mentioned and future research will reveal still more. I have emphasized the significance of the degree of acceptance of the modern pattern of culture for economic development in agriculture. This does not mean, of course, that there are no other sociological factors of importance, nor that this factor will have the same importance in the future as it has now. But it seems to me that in the present situation the most valuable contribution rural sociology can make to economic development in agriculture is to identify the social conditions in the countryside which are hampering the development of the modern dynamic pattern of culture, and the means necessary to change these conditions, so far as this is possible and desirable.

\section{U. A. AzIz, University of Malaya, Kuala Lumpur, Malaya}

I shall open the discussion by attempting three things : a brief note of Professor Hofstee's main points, a few comments on his points (some assessment of what he has included and what he has left out), and an indication of the main lines along which I think gaps may be filled.

Professor Hofstee approaches the topic with two main ideas and one basic question.

Firstly, he says, economic development in agriculture depends on farmers having a willingness for change-in fact they have to accept change not only as a good thing but as a routine aspect of life. Then they are the modern dynamic farmers and no longer traditionalistic ones. Secondly, he believes that change is abnormal in human society which has a basic tendency towards traditionalism.

Professor Hofstee's fundamental question, therefore, is, what hampers the metamorphosis of a society from the traditional state to that of the modern dynamic. I hope I have put the essence of his view faitly. I believe his approach is adequate for certain purposes and it is not unsound provided we realize the limitations involved.

In commenting on the adequacy or otherwise of the paper we should examine the criteria that have been adopted for including certain topics and for excluding others. Professor Hofstee has 